\title{
DESIGUALDADES E POLÍTICAS - O PAPEL DA CIÊNCIA*
}

\author{
Kelen Christina Leite ${ }^{1}$
}

Eu gostaria de começar dizendo que algumas, ou muitas das coisas que preparei, já foram levantadas e trabalhadas pelo Renato em sua fala, deste modo talvez eu só cite algumas coisas para pontuar o pensamento, mas eu não vou entrar nos detalhes porque as coisas já foram ditas e muito bem ditas por ele.

Esse Seminário Ciência, Politicas e Metodologias de Pesquisa: diálogos Brasil e Portugal se coloca, por objetivo, tratar de questões relacionadas às pesquisas em Ciências Humanas e sua colaboração na análise e elaboração de políticas e, sobretudo, de políticas públicas; assim como os desafios e conquistas metodológicas de integração entre essa área e à de utilização de dados, de dados armazenados, que são produzidos e sistematizados em meios digitais. A descrição do evento ressalta, ainda, que, desde que diversas disciplinas dessa grande área - a exemplo da Sociologia, Psicologia, Comunicação, Antropologia - passaram a se debruçar mais fortemente sobre as questões das desigualdades e suas relações com os direitos de minorias, suas contribuições tornaram-se fundamentais para a construção de indicativos de políticas públicas que atendam a essas minorias.

Assim, as questões e os dados de desigualdade social e espacial, capital social, mobilidade, estudos urbanos e rurais, gênero e sexualidade, direito à comunicação, relações de trabalho, relações intergeracionais e outras têm recebido a atenção interdisciplinar da área de humanas também no sentido de analisar as políticas públicas existentes e/ou trazer novos dados para elaboração de novas políticas.

*DOI- 10.29388/978-65-86678-33-8-0-f.15-30

${ }^{1}$ LEITE, K. Desigualdade e Políticas: o Papel da Ciência - Kelen Leite. 2018. (48m11s). Youtube. Disponível em: <https://www.youtube.com $/$ watch?v $=$ C76b0VxIe-A >. Acesso em: 10 out. 2020. 
Por outro lado, as Ciências Humanas, como qualquer outra área do conhecimento, têm suas fronteiras cada vez menos delimitadas, recebendo a contribuição de outras áreas. Ao se pensar a pesquisa e suas metodologias, torna-se cada vez mais comum utilizar dados, metodologias e técnicas das ciências de dados. Assim, as disciplinas da área de exatas trazem subsídios para novas formas de fazer pesquisa na área de humanas, encontrando-se em um ponto de intersecção entre esses grandes campos do conhecimento. Acrescentaria, ainda, que muito também se tem feito com a grande área das ciências naturais.

Deste modo, este evento pretende oportunizar o diálogo entre as áreas, assim como apresentar experiências realizadas ou em andamento situadas nessa interface para serem debatidas de modo interdisciplinar, reforçando a emergência de se enfrentar os desafios que as pesquisas afrontam na sociedade contemporânea, especialmente se considerarmos os contextos das dinâmicas sociais e suas permeabilidades.

Assim, a proposta desse seminário abre um leque de possibilidades quase infinitas para a discussão; é uma proposta muito ambiciosa, um longo programa de pesquisa. No entanto, cabe-nos, aqui nesta mesa, discutir: "Desigualdades e Políticas: o papel da Ciência".

Entendo que, embora um pouco menos vasta que a proposta geral do evento, ainda assim temos um debate que abrange vários temas, vários conceitos e perspectivas diversas sobre: desigualdade; ou seja, o que se entende por desigualdade? Quais são seus componentes? Quais são as variáveis determinantes? A desigualdade é aqui pensada em termos relativos e/ou absolutos? Sob qual perspectiva pensaremos a desigualdade? Liberal? Progressista? Conservadora? Comunitarista? A partir da esquerda, da direita? Enfim... são inúmeras as possibilidades.

Nossa mesa deve, ou deveria, falar também sobre políticas e sobre ciência, ou seja, deveríamos articular esses termos para situar o que são desigualdades e como estão dadas as desigualdades sociais, econômicas, políticas, as diferenças culturais que, por sua vez, produzem e/ou reproduzem desigualdades e tantas outras questões.

Se pensarmos a política, outro tema proposto para essa mesa, devemos pensar, antes de qualquer coisa, o que entendemos por política, palavra que hoje, no Brasil e não apenas, está desgastada, questionada, con- 
denada etc. Mas o que é a política e o que existe, se é que existe, fora da política? Por fim, o outro termo da proposta dessa mesa é ciência, mais uma vez um tema vastíssimo: o que entendemos por ciência? O que entendemos sobre seus métodos, suas metodologias, sobre sua: objetividade; verificabilidade; falseamento; racionalidade; falibilidade, seus paradigmas, suas revoluções científicas, ou seja, apenas citando esses nove termos já estaríamos discutindo distintas perspectivas sobre o que é e o que não é ciência e, por fim, teríamos que nos ater às ciências humanas; portanto, um outro campo vasto de discussões.

Assim, confesso, encontrei-me em meio a um certo desespero sobre o que falar neste seminário. Deste modo, eu resolvi organizar uma fala que se articula muito mais a partir de vários questionamentos e, possivelmente, nenhuma resposta específica em torno das desigualdades, das políticas e do papel da ciência nestas questões.

Então, partindo de alguns autores e autoras, como Rosi Braidotti, Donna Haraway, dentre outras e outros, por exemplo, seria interessante nos indagarmos se sempre fomos humanos. Quando estamos pensando a questão das ciências humanas, o que é esse humano de que tanto falamos? O que é a condição humana, e o que seria uma condição póshumana - aliás, isso tem a ver com a proposta que o Márcio falou no início, a proposta desta Pós-Graduação Interdisciplinar que estamos elaborando.

Para essas autoras, então, a questão que se coloca é que, ainda hoje, 2017, alguns de nós não somos considerados completamente humanos, ainda que, desde o iluminismo se tentasse colocar o sujeito cartesiano, racional, cidadão no centro do debate, construindo, desse modo, a noção de direitos e aqui, especificamente, gostaria de centrar na construção dos chamados direitos humanos dentro, evidentemente, dos limites postos pela própria sociedade burguesa, pela sociedade capitalista, pois é desta sociedade, e a partir desta sociedade, que nós estamos falando. Assim a própria noção e construção de direitos e da definição do humano é pautada por esse modo de organizarmos a produção e a reprodução da vida social, ou seja, falaremos dentro desses limites.

Assim, esses termos (humano, direitos etc) parecem ter sido aceitos e "consensuados", ainda que sempre tenha havido um abismo entre 
as definições abstratas e a concretude da vida cotidiana. Se tivermos presente, por exemplo, a imagem do Homem Vitruviano de Leonardo da Vinci, temos a demonstração deste paradigma do humanismo que sempre colocou no centro do debate o humano, entendido esse humano como o homem universal, com uma determinada representação, com uma determinada perfeição, essa representação, aceita pela sociedade, aceita pela ciência, aceita pela academia, aceita pela igreja, e esse humano que está no centro de tudo e é a medida de todas as coisas, quem é?

Quem é esse humano medida de todas as coisas? Essa pergunta é importante, pois isso tem a ver com as desigualdades, pois esse humano é um homem, um homem racional, branco, europeu, colonizador, conquistador, heterossexual, ou seja, o homem, ou aquilo que é o humano e que é tomado como medida de todas as coisas. É esse homem bem específico, bem definido e não outro. Portanto, a partir daí, já podemos perceber como isso dará o contorno para várias dimensões da e sobre a desigualdade.

O Renato, que antecedeu a minha fala, tocou, por exemplo nas desigualdades de gênero que também são multidimensionais, assim, a imagem desse homem universal, pode e deve ser absolutamente questionada, uma vez que ela não representa a humanidade, uma vez que, na concretude, na materialidade da vida cotidiana, uns parecem ser mais humanos do que outros ou outras, e por quê? Porque a diferença acaba sendo transformada em desigualdade e em inferioridade, e essa é uma das questões, ou uma das marcas da diferença quando transformada em desigualdade de corpos que são necessariamente sexualizados, racializados, naturalizados, empobrecidos, generificados, reduzidos a um standard, desses do tipo uso e jogo fora ou, como diria Butler, dos corpos que não importam. Portanto, esse homem ou esse humano universal repleto de interesses de classe, sexo, raça, gênero e genoma deve ser questionado, deve ser interpelado. São aqueles os corpos descartáveis?

Nesses termos, esse homem, esse humano, pensado a partir desta perspectiva precisa e deve ser questionado, ele precisa ser descentrado, assim esse paradigma que podemos até entender como um paradigma eurocêntrico, mas que também nos constitui e coloniza nosso pensamento, implica a dialética entre eu e o outro, bem como a lógica da identida- 
de, atuando como motores de uma lógica cultural de um certo humanismo universal.

Então, o que é central para este paradigma universalista e para esta lógica binária - o zero/um ao qual se refere o logo do seminário - é, portanto, a noção da diferença, entendida no sentido aqui colocado, no sentido pejorativo, uma vez que ela assume muitas vezes o sentido da inferioridade, assume conotações que são conotações essencialistas e que são, na verdade, letais do ponto de vista das pessoas que são marcadas como sendo as outras, as diferentes.

Podemos até voltar a Beauvoir, que se referia a esse outro, a esse segundo sexo como a "outrice", mas podemos pensar esse outro em várias escalas e não apenas pensando a questão de gênero. Então essas são as questões que traremos e são os questionamentos colocados no centro do debate, por exemplo, pelos chamados novos movimentos sociais das décadas de 1960/70 e que questionavam aquilo que estava posto também nas ciências humanas, os paradigmas, os pensamentos e o modo de olhar as coisas.

Passa a estar presente na discussão o anticolonialismo, o antirracismo, as questões ecológicas, então, cabe às ciências humanas o papel de tentar realizar e aprofundar estes questionamentos e, a partir deles, reinventar-se, repensar-se, recolocar-se, realocar-se, reassentar-se, e isso já vem sendo feito, seja pelos questionamentos de estudos que percorrem os caminhos da pós-colonialidade, dos estudos feministas, do novo materialismo, do neomarxismo, do pós ou trans-humanismo, enfim, há pessoas e grupos que estão colocando estas questões no centro do debate e estão tentando olhar para elas a partir de perspectivas distintas, de perspectivas diversas.

O Renato também apontou que as questões de classe, por exemplo, no final dos anos de 1980, mas sobretudo nos anos 90, também foram muito questionadas, como se esse conceito e conceitos ligados a essa perspectiva não conseguissem mais dar conta de explicar a realidade, e ocorre um certo esvaziamento do conceito e uma certa despolitização daquilo que está sendo pensado, produzido e discutido. Mas se percebe também que, nos últimos anos, há um olhar um pouco diferente quanto a estas categorias e esses conceitos, os quais precisam ser (re)utilizados, 
(re)propostos, retomados, porque eles ainda dão conta de um aspecto importante da realidade, embora eles não expliquem toda a realidade.

Nessa perspectiva, em relação às desigualdades, faz-se importante ressaltar que a desigualdade não é um termo absoluto. Ela sempre se coloca em relação a alguma outra coisa. É, portanto, um termo relacional que assume valência diversa em tempo e espaços também diversos.

A distribuição de riqueza, por exemplo, deve ser pensada desse modo e, sobre isto, persistem, pelo menos, duas visões que são contrapostas ou antagônicas: uma visão mais ligada à tradição marxiana e/ou marxista que pontua o fato de que a acumulação de capital nas mãos de poucos pode conduzir, inevitavelmente, à concentração da renda e da riqueza e, portanto, essa concentração é geradora de desigualdade que tende a ser sempre maior. Outros, por uma vertente liberal, entendem que o desenvolvimento econômico - a acumulação de capital - juntamente com o desenvolvimento tecnológico e científico são capazes de, como uma onda, elevar a todos.

Claro que existe muita coisa entre essas duas posições, mas que não nos cabe abordar aqui. Assim, se tivemos breves períodos na história como os chamados 30 anos gloriosos do capitalismo, marcados pela construção do welfare state, sobretudo para os países ditos centrais em que a onda foi, medianamente, capaz de elevar muitos ou alguns. É bom frisar que esse foi apenas um breve período, um curto período na história que entra em crise a partir dos anos de 1970 em que esse modo de regulação fordista-keynesianista, calcado em uma política de compromisso entre capital e trabalho mediado pelo Estado se rompe. E vemos esse estado social: este estado protetor sendo questionado em seus pressupostos e as políticas neoliberais sendo introduzida, enfraquecendo estas estruturas.

Isso significa que existem estruturas profundamente desiguais que sustentam o capitalismo, assim, ele produz desigualdades que ameaçam e colocam em xeque o próprio conceito da meritocracia sobre o qual se fundam as chamadas e autorreferenciadas sociedades liberais e democráticas.

Há quem acredite e sustente, no entanto, que a "democracia pode retomar o controle do capitalismo e assegurar que o interesse geral da 
população tenha precedência sobre os interesses privados, preservando o grau de abertura econômica e repelindo retrocessos protecionistas e nacionalistas". Quem parte desta perspectiva é Thomas Piketty, um economista francês que publicou um livro cujo título, um pouco audacioso, é: O Capital no século XXI. Em muitos lugares foi aclamado quase como o novo Marx, como se pudesse simplesmente existir um novo Marx em termos reformistas, um Marx colocado em termos de uma social democracia.

Ainda que haja uma escassez de dados para projetarmos séries históricas e entendermos melhor a dinâmica da desigualdade, sobretudo econômica, Piketty trouxe à luz, por exemplo - a partir do trabalho que ele desenvolveu conjuntamente com muitos outros pesquisadores - que foi necessário esperar o último terço do século XIX para observar um aumento do poder de compra dos salários, enquanto o capital só aumentava tremendamente sua fatia na renda nacional.

Os dados por eles coletados indicam que não houve nenhuma redução estrutural da desigualdade antes da IGM. De 1870 a 1914 o que ocorreu foi uma estabilização da desigualdade em nível elevado e, em vários casos, a desigualdade foi acompanhada de uma concentração cada vez maior da renda e da riqueza.

Desse modo, a questão da desigualdade sempre foi um tema presente e voltou com força a partir da crise dos anos de 1970, período a partir do qual a desigualdade volta a aumentar também nos países ricos, sobretudo nos EUA, país em que, na primeira década do século XXI, a concentração de renda atingiu, na verdade excedeu, o nível recorde visto nos anos de 1910-1920.

Pode-se dizer que, no início do século XXI, estamos nos mesmos termos em que nos encontrávamos no século XIX: transformações impressionantes ocorrendo com velocidade, mas não sabemos em que direção irão e que rumo tomará a distribuição de renda.

As questões que precisam ser colocadas no centro do debate parecem retomar as questões dos velhos socialistas utópicos, ou seja, de que serve o desenvolvimento industrial - e, hoje, não apenas esse; de que servem as inovações tecnológicas, a biotecnologia, a nanotecnologia, a realidade aumentada, a biogenética, os deslocamentos populacionais? Se 
a cabo de meio século de crescimento da indústria a situação das massas continua tão miserável quanto antes, e se tudo que o Estado pode fazer parece ser proibir que crianças menores de oito anos trabalhem nas fábricas.

Todos esses avanços presentes nas sociedades não conseguiram resolver, minimamente, as questões das desigualdades, na verdade, esses avanços tecnológicos podem, dependendo da política que se adote, aumentar e reproduzir ainda mais as desigualdades.

Aqui neste seminário, estamos falando de métodos e metodologias, nesse sentido, o livro de Piketty traz uma contribuição importante, pois ele conseguiu unir um grupo grande de pesquisadores - para além das problemáticas específicas, pois os países dimensionam estas coisas de modos diferentes, então não é tão simples conseguir comparar os dados e etc -, que conseguiram trabalhando sobre duas fontes principais: uma série de dados que lida diretamente com a desigualdade e a distribuição de renda; e uma outra série de dados que lida com a distribuição da riqueza e a relação entre riqueza e renda.

Suas conclusões, no entanto, não poderiam ser outra senão atestar que a

[...] evolução dinâmica de uma economia de mercado e de propriedade privada, deixada à sua própria sorte, contém forças de convergência importantes, ligadas, sobretudo à difusão do conhecimento e das qualificações, mas também forças divergentes vigorosas e potencialmente ameaçadoras para nossas sociedades democráticas e para os valores de justiça social sobre os quais elas se fundam. A desigualdade faz com que os patrimônios originados no passado se recapitalizem mais rápido do que a progressão da produção e dos salários. Aqui há uma contradição lógica fundamental. O empresário tende inevitavelmente a se transformar em repentista e a dominar cada vez mais aqueles que só possuem sua força de trabalho. Uma vez construído, o capital se reproduz sozinho, mais rápido do que cresce a produção. É como se o passado devorasse o futuro (PIKETTY, 2015, p. 555).

É também devido a questões como essas que, como já ressaltado anteriormente nesta mesa, temos a proposta da reforma da previdência 
sendo pautada nos termos em que está sendo pautada, além do que já ocorreu com a reforma, ou melhor, com o ataque, o desmonte, a contrarregulação do trabalho nesse país, promovida pelo atual governo. Por exemplo, eu estava vendo uma notícia que pedagogos já estão sendo contratados via contrato intermitente de trabalho por $\mathrm{R} \$ 5,28$ reais a hora trabalhada, e apenas a hora trabalhada. Isso faz parte deste processo.

Nesse sentido, se olharmos, por exemplo alguns indicadores dos Estados Unidos, percebemos que muitos deles encontram-se no mesmo nível de indicadores dos países em desenvolvimento. O relatório mais recente do Programa das Nações Unidas para o Desenvolvimento (PNUD) indica que a expectativa de vida dos americanos é de 79,2 anos. Esse dado coloca o país como o $40^{\circ}$ do mundo, atrás de um conjunto de países desenvolvidos, mas também de alguns países latino-americanos, como Chile, Costa Rica e Cuba. No Brasil, a expectativa de vida é de apenas cinco anos menos do que a dos EUA, ou seja, 74,7 anos.

Com isso percebemos o quanto estas diferenças, estas desigualdades estão postas também no interior dos países ditos centrais ou desenvolvidos. E, quando desagregamos esses dados, ou a partir deles trabalhamos as várias dimensões que esses dados possuem, encontramos outras questões relevantes também, pois esse mesmo estudo do PNUD sobre a expectativa de vida nos Estados Unidos, por exemplo, vai dizer que o homem branco com educação universitária tem uma expectativa de vida de 80 anos, enquanto o homem afro-americano com baixa escolaridade tem uma expectativa de 66 anos. Então, no interior do próprio país, há uma expectativa de vida para um contingente dessa população que é de 66 anos, enquanto para outro contingente da população a expectativa de vida é de 80 anos.

No Brasil, temos disparidades em relação à questão regional, mas também disparidades relacionadas à raça/etnia. O IBGE destaca um pouco a diferença de expectativa de vida entre as regiões do país. Mas, se entrarmos nessas regiões do país, perceberemos ainda uma série de diferenças em relação à expectativa de vida, ou, ainda, percebermos as diferenças a partir dos indicadores de cor, sexo e domicílio.

A partir desses dados, percebemos o quanto a questão de gênero e a questão de raça/etnia, além de considerar os dados referentes ao es- 
paço urbano e espaço rural, geram diferenças, ou melhor, desigualdades enormes entre as regiões do país. A renda, por exemplo, é bastante diferente, sobretudo para a população negra, o índice de Gini também demonstra essas disparidades.

Os números sobre mortalidade infantil, neste mesmo estudo do PNUD para os EUA, por exemplo, traz uma situação que o coloca ao lado de vários países em desenvolvimento e tantos outros dados relacionados a eles. Em relação ao número de crianças que morrem por mil nascidos vivos, temos uma média de 5,6 nos EUA. Isso coloca esse país no $44^{\circ}$ lugar do mundo, novamente superado pelos países ricos como um todo, bem como por Cuba, Bósnia e Croácia, mas, quando se desagrega os dados e olha-se para a questão dos afro-americanos, os dados são outros, ou seja, sobe para 46 por mil nascidos vivos, dados que aproximam os EUA a países como Togo e Ilha de Granada. A mesma coisa acontece no Brasil, quando desagregamos os dados encontramos sempre a população negra do país em situação pior que a população branca.

Eu havia preparado, ainda, dados em relação à pobreza infantil, segurança pessoal, educação e outros, mas como isso já foi abordado pelos colegas que me precederam eu deixarei de lado e tentarei pensar com vocês algumas questões relacionadas especificamente ao Brasil.

O Brasil sempre se caracterizou por ser um país rico e com uma grande quantidade de pessoas vivendo na pobreza e na miséria, ou seja, o Brasil nunca foi um país pobre, mas sempre foi um país de muitos pobres. Daí o slogan tão criticado, mas tão acertado a meu ver, da Presidenta Dilma, cujo mandato popular se encerraria em 2018, quando ela diz que: "país rico é país sem pobreza", esse foi um slogan absolutamente questionado, mais que questionado, ridicularizado, quando, na verdade, ele é um slogan de um governo que diz a que veio, porque de fato, país rico deveria ser um país sem pobreza, um país sem pobres. Então, como podemos falar de um país que está entre as dez maiores economias do mundo, chegando a ser a quinta economia do mundo no período Lula/Dilma e, no entanto, colocá-lo como um dos países mais desiguais do planeta?

Essa pobreza escandalosa de nosso país relaciona-se com nossa história marcada pelo colonialismo, pelo patrimonialismo, pelo pensamento oligárquico de uma elite misógina, racista, sexista, classista que ja- 
mais foi capaz de pensar o desenvolvimento do capitalismo no país associado a bens sociais para a população. Uma elite que jamais conseguiu pensar as políticas públicas enquanto aquelas que deveriam estar voltadas ao bem-estar da população, pois, neste país, as questões sociais sempre foram caso de polícia e não caso de política. Foi apenas nos últimos anos, contrariamente ao que está ocorrendo em Portugal, hoje que - não sem enormes contradições e enormes equívocos, mas estas contradições e estes equívocos também são fruto da nossa história - tivemos políticas públicas que tentaram minorar esta dimensão da desigualdade, não apenas com políticas assistenciais, mas com políticas que pretendiam alterar estruturalmente o estado de coisas em um país tão rico como o Brasil que figura, a depender das contingências, entre a décima e a quinta economia do mundo, e tão pobre ao mesmo tempo.

Ainda que a desigualdade tenha diminuído de 2002 até o golpe palaciano e parlamentar impetrado contra o mandato da Presidenta Dilma, ela ainda permanece em níveis inaceitáveis. Seriam necessárias décadas de políticas públicas voltadas a essas questões para vermos um país um pouco diferente.

A desigualdade, no entanto, deve ser entendida sempre como um fenômeno que é multidimensional, é relacional, é generificada, racializada etc. Podemos, para ter uma ideia, partir da dimensão mais evidente da desigualdade que poderia ser destacada pelo Coeficiente de Gini, que aponta a diferença entre os rendimentos dos mais pobres e mais ricos e demonstra, portanto, a desigualdade de renda.

Então, se pegarmos o índice de Gini para o Brasil a partir de 1995, percebemos que o país veio, ano a ano, tendo uma queda da desigualdade, uma queda pequena, mas é uma queda importante, e ela trazia um pouco a ideia de um certo ânimo em relação a esses dados, no sentido que víamos uma queda crescente, porque parecia que era uma tendência que se poderia manter no tempo.

Olhando para dados que são um pouco anteriores ainda e vão até 2014, podemos separar um pouco os distintos governos, ou seja, o governo Itamar, o governo Fernando Henrique, o governo Lula e o governo Dilma, e percebemos essa queda crescente e mais acentuada a partir do governo Lula. Mas o que mais vemos aqui? 
Se voltarmos um pouco para algumas décadas atrás, vamos perceber que em janeiro de 2012 estávamos no mesmo nível de desigualdade que estávamos em 1960, logo, o país, nestes últimos anos, avançou nesta direção, porém nos colocou em um patamar da década de 1960, e o mais grave nesse sentido é que, agora, não vemos mais a possibilidade que aquela queda volte a ocorrer com as políticas que estão colocadas na mesa por esse governo; pelo contrário, as políticas que estão postas hoje para o país são políticas que vão acentuar esta desigualdade.

Uma coisa interessante, também, é que, se olharmos para esses dados e pegarmos as análises ou as conclusões do Piketty, perceberemos que nos colocar no patamar da década de 1960 é um pouco a perspectiva que existe também de alguns dados que são dados globais.

Então, os dados que trazemos, sobretudo a partir dos dados PNUD sobre o coeficiente de Gini, coloca o Brasil nas piores posições. São poucos os países que estão piores do que nós. Assim, os dados mostram a assertividade da Presidenta Dilma com seu slogan: país rico épaís sem pobreza, pois embora tenhamos sido, em seu período, a quita economia do mundo, estamos também entre os dez países que possuem a pior distribuição de renda.

Embora esse índice nos ajude a ter uma visualização e estabelecer comparações com outros países, ele apresenta um problema que é olhar um único aspecto, ou seja, a renda monetária. Porém, considerando esse índice, os dados mostram, claramente, uma queda na desigualdade de renda no período de 2002 a 2015. Entre 1980 e 2001, o Coeficiente ficou estagnado no elevado patamar de 0.59, caindo em 2015, ao nível mais baixo da história, ou seja, 0.49 .

Ainda em relação à avaliação de renda, por exemplo, o que temos entre 2002 e 2015, é um sinal e reflete a queda da desigualdade que podemos perceber por esses dados, aqui comentados, e das políticas públicas que estavam voltadas a uma parcela específica da população. Percebemos, assim que o aumento da renda dos $20 \%$ mais pobres foi bem maior que o aumento da renda dos $20 \%$ mais ricos, por exemplo, e aqui estamos falando apenas de assalariados.

Porém, outros dados são importantes para uma análise da desigualdade. O salário mínimo, por exemplo é um deles e teve, nos últimos 
anos, aumentos reais. Teve-se formalização do mercado de trabalho, incorporação dos mais pobres ao orçamento federal etc. Esses são apenas, rapidamente, alguns dados que nos situam quanto às questões da desigualdade. Não temos tempo aqui, mas recentemente saiu um estudo tratando especificamente da desigualdade levando em conta outros elementos importantes para qualificar melhor a desigualdade que tem a ver com acesso a bens de consumo, infraestrutura, saúde, educação, habitação etc.

Eu gostaria de falar um pouco, especificamente, sobre a questão das universidades. As falas iniciais deste Seminário também tiveram um tom de protesto, de repúdio àquilo que vem acontecendo com as universidades brasileiras, sobretudo com as universidades federais. Então, o último elemento que eu gostaria de colocar, de ressaltar e trazer para o debate, diz respeito à questão da ciência e da tecnologia.

Tivemos, nos últimos anos, um investimento vultuoso que trouxe melhoria em vários índices para o país, associado a um investimento nas universidades federais que haviam sido absolutamente sucateadas, asfixiadas, chegando à beira da privatização no governo do presidente, sociólogo, professor, pesquisador universitário, senhor Fernando Henrique Cardoso.

O resultado desse período é que, hoje, temos 63 Instituições Federais de Ensino Superior que vinculam 328 campi espalhados pelos país todo, o campus Sorocaba da UFSCar é fruto desta política iniciada pelo Presidente Lula.

Além do ensino de graduação, dos programas de mestrado e doutorado, para cerca de um milhão e duzentos mil alunos, as universidades federais são, também, responsáveis por uma rede de equipamentos públicos e de serviços que atendem à população nas mais diversas áreas, incluindo: 46 hospitais universitários de alta complexidade (em muitos casos, únicas alternativas em suas áreas de atuação no Sistema Único de Saúde); clínicas e laboratórios; museus; teatros; cinemas; escolas de música, teatro e dança; agências de inovação; incubadoras de empresas de base tecnológica e parques de ciência e tecnologia; clínicas de direitos humanos; escritórios de assistência jurídica à população carente; serviços de atenção à saúde mental e escritórios modelo. Educação, ciência, arte, cultura e cidadania são resultados diretos do trabalho das universidades fe- 
derais.

Desse modo, é importante frisar que, ao longo da última década, o Sistema Público de Universidades Federais expandiu-se em todas as direções.

O número de alunos dobrou. Novas universidades, novos campi e novos cursos foram criados, em sintonia com o processo de desenvolvimento do país. A atividade de pesquisa contribuiu para, em uma década, levar o Brasil de $23^{\circ}$ para $13^{\circ}$ posição entre as nações que mais produzem ciência. É um salto gigantesco, se pensarmos que tudo isso foi realizado em tão pouco tempo.

O sistema também evoluiu qualitativamente. A proporção de docentes com mestrado e doutorado cresceu de 49\%, em 1995, para $91 \%$, em 2015. A proporção do número de alunos de pós-graduação passou de $6 \%$, em 2005, para $11 \%$, em 2015, não obstante a duplicação das vagas na graduação no mesmo período. O número de programas de pós-graduação recomendados pela CAPES passou de 714, em 1998, para 2.147, em 2015. O Índice Geral de Cursos das universidades federais passou de 3,70, em 2007, para 3,94, em 2015. O conceito médio dos Programas de Pós-Graduação passou de 4,00, em 2000, para 4,34, em 2016.

Não há, no Brasil, um sistema de formação de recursos humanos, produção de conhecimento, desenvolvimento tecnológico, prestação de serviços à sociedade e promoção da cidadania comparável ao Sistema Público de Universidades Federais. Em outras nações, que contam com sistemas com as mesmas características, as instituições são, como regra, também públicas, sob a responsabilidade direta do Estado, portanto é necessário prestar atenção e desmistificar o discurso daqueles que apregoam a privatização das universidades federais.

A crise política e financeira ocasionada com o golpe palaciano e parlamentar retirou recursos da Ciência e Tecnologia. A comunidade científica afirma que o orçamento de investimentos do setor passou de $\mathbf{R} \mathbf{\$}$ 8,4 bilhões em 2014 para $R \$ 3,2$ bilhões este ano. Para 2018, o programado é ainda menor, de $\mathbf{R} \$ \mathbf{2 , 7}$ bilhões, concluindo essa fala que deveria versar sobre Desigualdades, Políticas e Ciência gostaria de finalizar com algumas questões:

As universidades estão, em certo sentido, sob ataque. Isso ocorre 
não apenas no Brasil, mas no mundo todo. Há uma lógica rentista e privatista que absorve a tudo e a todos e que se move por trás desses ataques.

Em nosso caso, especificamente, além das questões financeiras, privatistas etc, quero me ater a uma questão muito preocupante que está ocorrendo nas universidades. Estamos sofrendo uma forte repressão, forte cerceamento ao debate e à crítica que ocorre no espaço da universidade e os exemplos são inúmeros: projetos de agências de fomento sendo recusados e a recusa, expressa em pareceres, é ligada ao referencial teórico/metodológico utilizado pelo docente/pesquisador, por exemplo o referencial marxista. Temos ameaças explícitas e intimidatórias nos temas de gênero e sexualidade, como, por exemplo, o absurdo de ter a defesa de uma aluna de mestrado garantida por agentes da polícia, pois a dissertação era sobre o tema de gênero e sexualidade e havia várias ameaças envolvendo a defesa da aluna. Além disso, professores da Universidade Federal da Bahia estão recebendo ameaças por trabalharem com questões de gênero e sexualidade.

Na USP, em Piracicaba, tivemos abertura de sindicância interna contra um docente que trabalha, há anos, com o MST. Tivemos, mais recentemente, a morte de um reitor acusado de desvio de dinheiro na operação "ouvidos mocos", quando, na realidade, ele nem reitor era no período em questão, além de ter sido anunciado um desvio de 800 milhões, quando, na verdade, esse era o total recebido por anos de implementação de um programa específico e, pior ainda, parece que tudo não passou de um grande engano, mas o reitor se suicidou pela humilhação que sofreu ${ }^{2}$.

Tivemos, também, a condução coercitiva do reitor e da vice-reitora da UFMG, com mais oito docentes da universidade, e esse caso é emblemático, porque tem a ver com um memorial sobre a ditadura, assunto que parece proibido nesse país e com o qual o país ainda não fez as contas devidas. Essa vice-reitora, que foi levada coercitivamente ontem, foi eleita em eleições para assumir a reitoria. O Conselho Universitário deve elaborar a lista tríplice na próxima semana, então, também, há

\footnotetext{
${ }^{2}$ Recentemente a investigação chegou a conclusão que nada poderia ser provado contra o Reitor. No entanto, o método do linchamento e do espetáculo não será capaz de trazê-lo à vida e, certamente, ninguém responderá por isso.
} 
um temor muito grande que ela não seja a indicada da lista tríplice pelo senhor Michel Temer. O nome da operação é: "a esperança e o equilibrista", um nome absolutamente sarcástico.

Podemos acrescentar a isso, o orçamento das universidades, que está ameaçado, bem como o orçamento de ciência e tecnologia, lembrando que a maior produção científica do país se dá no interior das universidades públicas, sendo o maior deles o sistema federal, paralisando, portanto, o desenvolvimento científico e tecnológico do país e, consequentemente, as possibilidades de mitigar as desigualdades por meio do conhecimento que é produzido no interior das universidades,

Temos, ainda, uma política calcada, hoje, em um pensamento conservador, beirando o fascismo, e transformando a vida de pessoas LGBTQIA+, negras, indígenas, mulheres em vidas que não importam, em corpos que não importam - isso não apenas ao Estado - mas também não importam à sociedade brasileira, às escolas brasileiras, às famílias brasileiras e aos ditos cidadãos de bem.

Assim, o ano de 2018 não deixa de ser um ano decisivo não apenas em relação às desigualdades, às políticas e à ciência no Brasil, como também um ano-chave para a escolha de que país queremos, de que sociedade queremos, se uma sociedade minimamente democrática e equânime, ainda que nos limites de uma democracia burguesa, ou simplesmente uma sociedade burguesa, autoritária e fascista.

\section{Referência}

PIKETY, Thomaz. O Capital no século XXI. São Paulo: Intrínseca, 2015. 